\title{
TRATAMIENTO PSICOLÓGICO Y LA REPARACIÓN \\ INTEGRAL DEL DAÑO EN CASO DE VIOLENCIA \\ FAMILIAR: JUSTICIA RESTAURATIVA
}

\section{PSYCHOLOGICAL TREATMENT AND COMPREHENSIVE DAMAGE REPAIR IN THE EVENT OF FAMILY VIOLENCE: RESTORATIVE JUSTICE}

\author{
Noresma Taba Moreno ${ }^{1 *}$ (iD). \\ 1. Centro de Especialización Judicial del Tribunal Superior de Justicia del Estado de Tabasco, México. \\ noresma_taba@hotmail.com \\ * Autor de correspondencia: Noresma Taba Moreno, correo electrónico: noresma_taba@hotmail.com
}

\section{RESUMEN}

La justicia restaurativa es una herramienta para que las partes involucradas en un proceso judicial obtengan un resarcimiento en los bienes vulnerados. El presente artículo pretende describir respecto al alcance de las víctimas involucradas en un proceso de violencia familiar, delimitado a los supuestos en donde cohabiten como hijos, niños, niñas y adolescentes, ante el Juez de Control en las situaciones de arribo a la salida alterna de suspensión condicional, sea impuesta oficiosamente con independencia de las demás condiciones a cumplir durante la misma, el tratamiento psicológico que establece el artículo 195, fracción VII del Código Nacional de Procedimientos Penales. Considerando que el delito de violencia familiar, tutela la convivencia armónica del vínculo familiar, no de las relaciones de parentesco civil, el mismo es un ente consistente en la psique de las víctimas directas e indirectas, estas últimas por los daños colaterales de la ejecución del mismo. En ese orden de ideas, la tutela de los derechos de la víctima no puede constreñirse únicamente a la víctima directa, sino se obtiene una reparación del daño en la psique de quienes son lesionados por alienación parental, se estará coartando el derecho de acceso a la justicia. Al respecto, se aborda y justifica el hecho de que no es posible hablar de justicia restaurativa en una suspensión condicional a proceso, sin la observancia de manera oficiosa del tratamiento psicológico.

Palabras clave: derecho a la familia; protección; trastornos; suspensión condicional; víctimas indirectas.

Cómo citar:

Taba Moreno, Noresma. (2021). Tratamiento psicológico y la reparación integral del daño en caso de violencia familiar: justicia restaurativa. Revista de Investigaciones Universidad del Quindio, 33(S2), 91-98. https://doi.org/10.33975/riuq.vol33nS2.617 


\begin{abstract}
Restorative justice is a tool for the parties involved in a judicial process to obtain compensation for the damaged property. This article aims to describe the scope of the victims involved in a process of family violence, limited to the cases where they cohabit as children, boys, girls and adolescents, before the Control Judge in the situations of arrival at the alternate exit of conditional suspension, is officially imposed regardless of the other conditions to be met during the same, the psychological treatment established in article 195, section VII of the National Code of Criminal Procedures. Considering that the crime of family violence protects the harmonious coexistence of the family bond, not of civil kinship relations, it is an entity consisting of the psyche of the direct and indirect victims, the latter due to the collateral damage of the execution of the same. In that order of ideas, the protection of the rights of the victim cannot be restricted only to the direct victim, but a repair of the damage to the psyche of those who are injured by parental alienation is obtained, the right of access to the Justice. In this regard, the fact that it is not possible to speak of restorative justice in a conditional suspension of proceedings is addressed and justified, without the informal observance of psychological treatment.
\end{abstract}

Keywords: right to family; protection; disorders; conditional suspension; indirect victims.

\title{
INTRODUCCIÓN
}

El Código Penal del estado de Tabasco en su numeral 208 bis, establece se entenderá por violencia familiar al acto abusivo de poder, dirigido a someter o agredir de manera física, verbal, psicológica, patrimonial, económica o sexual a la víctima, dentro o fuera del domicilio familiar, o incurra en una omisión grave que atente contra su integridad física, psíquica o amabas; siempre y cuando el agresor tenga o haya tenido con ella relación de matrimonio, concubinato o de hecho, de parentesco por consanguinidad en línea recta ascendente o descendente sin limitación de grado, de parentesco colateral consanguíneo o afín hasta el cuarto grado, de adoptante o adoptado, o de tutor.

El objeto del derecho penal, se centra en la protección de los bienes jurídicos tutelados (Nares et al., 2015), en la violencia familiar este consiste en la convivencia armónica de la familia, por lo que el mismo en la Justicia Restaurativa (González, 2013) implica devolver al estado actual la psique de las víctimas del delito.

Siendo entonces que en el seno familiar se forma la identidad del individuo, el no garantizar un ambiente armónico es factor preponderante para que la cultura de violencia se repita y multiplique; S. Freud (2020), afirma que solemos repetir patrones de conducta de dos maneras: mediante patrones positivos, que nos ayudan a reafirmarnos en la vida y a realizarnos (fuerza de vida); y patrones negativos, que nos conducen a la autodestrucción y a la neurosis (fuerza de muerte)

El proceso judicial pareciera únicamente centrarse en garantizar la integridad física de la víctima (Taus, 2014), coadyuvando en la desintegración del vínculo familiar al establecer como condiciones el "no acercarse a la víctima" y en los casos que así lo requieran "pago de la pensión alimenticia"; esta es una situación que se repite en los procesos de suspensiones condicionales. En ese tenor se describe 
el alcance de la justicia restaurativa aplicable en el tratamiento psicológico y la reparación integral del daño en caso de violencia familiar.

\section{METODOLOGÍA}

El precepto de salvaguardar la integridad de toda persona implica en cualquiera circunstancia que pongan en riesgo su situación o en estado de vulnerabilidad. En casos de violencia familiar emergen conflictos y conductas que trasgreden la dignidad de una persona, en este caso de integrantes de la familia. En ese sentido, en las siguientes líneas se esboza el hecho de que no es posible hablar de justicia restaurativa en una suspensión condicional a proceso, sin la observancia de manera oficiosa del tratamiento psicológico. Para ello, el tema fue abordado desde una revisión doctrinal basado en el método documental, se interpretó aquellas normas referentes al tema desde el método exegético.

\section{RESULTADOS}

\section{Protección integral de la familia a partir de las normas jurídicas}

El numeral 195, fracción VII del Código Nacional de Procedimientos Penales (2014a), establece la posibilidad de imponer la condición para cumplir durante una suspensión condicional del tratamiento psicológico.

Las secuelas provenientes de un ambiente violento en la esfera familiar, conlleva a normalizar la violencia, por lo que dicho patrón conductual se reproduce con uno o varios integrantes del núcleo familiar.

La Ley General de los Derechos de Niñas, Niños y Adolescentes (2014b), publicada por decreto Presidencial el 4 de diciembre de 2014, establece los derechos que gozarán estos en nuestro país, garantiza a la niñez y adolescencia mexicana en su artículo 1, fracción IV la salvaguarda y protección de los mismos, la responsabilidad del Estado a través de la administración de justicia, dicho artículo a la letra dice:

"Establecer los principios rectores y criterios que orientarán la política nacional en materia de derechos de niñas, niños y adolescentes, así como las facultades, competencias, concurrencia y bases de coordinación entre la Federación, las entidades federativas, los municipios y las demarcaciones territoriales de la Ciudad de México; y la actuación de los Poderes Legislativo y Judicial, y los organismos constitucionales autónomos."

Refiere el numeral 2, de la citada ley general, que es de observancia obligatoria al momento de tomar una decisión que afecte a niños, niñas y adolescentes en lo individual o colectivo, se deberán evaluar y ponderar las posibles repercusiones a fin de salvaguardar su interés superior y sus garantías procesales.

Las autoridades tomarán las medidas para prevenir, y sancionar casos en que niñas niños adolescentes se vean afectados por conductas como el descuido la negligencia, maltrato, trabajo infantil, la coacción por participar en algún delito; al respecto es primordial destacar el artículo 4 de la Constitución Federal que establece referente a la familia:

Artículo 4o.- La mujer y el hombre son iguales ante la ley. Ésta protegerá la organización y el desarrollo de la familia. 
Toda persona tiene derecho a decidir de manera libre, responsable e informada sobre el número y el espaciamiento de sus hijos.

...

Toda familia tiene derecho a disfrutar de vivienda digna y decorosa. La Ley establecerá los instrumentos y apoyos necesarios a fin de alcanzar tal objetivo.

Respecto de la parte in fine del párrafo que precede, remito el sentido del artículo y destaco la "protección integral de la familia" para lo cual en el ámbito estatal la ley penal refiere la agresión armónica del vínculo familiar como el delito de violencia familiar previsto en el artículo 208 bis del Código Penal del Estado de Tabasco mediante el cual sanciona el acto abusivo de poder encaminado a someter o agredir de manera física, verbal, psicológica, patrimonial, económica o sexual, a la víctima dentro o fuera del domicilio familiar o incurran en una omisión grave que atente contra su integridad física psíquica o ambas; siempre y cuando el agresor tenga o haya tenido con la víctima relación de patrimonio concubinato o de hecho de parentesco por consanguinidad en línea recta ascendente o descendente sin limitación de grado, de pared colateral consanguíneo o afín hasta el cuarto grado de adoptante y adoptado o de tutor

Naciones Unidas define la violencia contra niñas niños y adolescentes como toda forma de perjuicio o abuso físico mental descuido o trato negligente malos tratos o explotación, incluida el abuso sexual tal y como lo Establece en el artículo 19 de la Convención sobre los Derechos del Niño (1989) el propio interés tan marcado de las distintas autoridades en sus respectivas esferas tiene su origen en aquellas acciones para redimir toda conducta que viole o ponga en riesgo la integridad de los niños, niñas y adolescentes.

Es precisamente dentro del seno familiar, por referir así, el ente conformado por los consortes, las distintas variantes; padre soltero o madre soltera, o persona distinta con la guarda o custodia del menor; el ente espacial en donde los menores conviven y a realizan su desarrollo psicoemocional.

El artículo 22 de la Ley General de los Derechos de Niñas, Niños y Adolescentes, obliga el derecho que tienen los menores a vivir en familia, por lo que, tendrán derecho a convivir o mantener relaciones personales y contacto directo con sus familiares de modo regular, excepto en los casos en que el órgano jurisdiccional competente determine que ello es contrario al interés superior de la niñez, sin perjuicio de las medidas cautelares y de protección que se dicten por las autoridades competentes en los procedimientos respectivos, en los que se deberá garantizar el derecho de audiencia de todas las partes involucradas, en especial de niñas, niños y adolescentes, acorde con lo normado en el numeral 23 de la citada Ley.

\section{Violencia familiar y su proceso jurídico de atención con justicia restaurativa}

En una aproximación de comprensión de violencia familiar, la Organización Mundial de la Salud, en el año 2002, publica el Informe Sobre la Violencia y la Salud, consistente en el estudio del problema de la violencia a escala mundial; la violencia puede definirse, pues, de muchas maneras, según quién lo haga y con qué propósito; la OMS define la violencia como: El uso deliberado de la fuerza física o el poder, ya sea en grado de amenaza o efectivo, contra uno mismo, otra persona o un grupo o comunidad, que cause o tenga muchas probabilidades de causar lesiones, muerte, daños psicológicos, trastornos del desarrollo o privaciones. Refiere el citado estudio, los cuatro niveles de raíces de la violencia: 
1. el individual

2. el relacional,

3. el comunitario $\mathrm{y}$

4. el social

Es en el nivel relacional que se investiga el modo en que las relaciones con la familia, los amigos, la pareja y los compañeros influyen en el comportamiento violento, teniendo en cuenta a tal efecto factores como el hecho de haber sufrido castigos fisicos severos durante la infancia, la falta de afecto y de vínculos emocionales, la pertenencia a una familia disfuncional, el tener amigos delincuentes o los conflictos conyugales o parentales. Por lo que se comprende que la violencia familiar trasciende del núcleo central de una familia e integra factores que influyen en el mismo como las relaciones sociales que se establece con otros grupos sociales.

Por lo que en las relaciones de violencia familiar en los núcleos constituido por padre, madre e hijo(s), atendiendo el hecho de que separar físicamente al activo y pasivo del delito, no garantiza una efectiva tutela de los derechos de la víctima u ofendido, por lo que si la víctima no accede a un tratamiento psicológico (Romero, 2010) para llevar a la sanidad el daño emocional de la víctima del delito de violencia familiar, no se estaría en condiciones del derecho de acceder a la reparación del daño, si se atiende con o la inexistencia de daños físicos, la violencia si conlleva a un daño emocional.

El artículo 187 del Código Nacional del Procedimientos Penales, en su penúltimo párrafo establece la improcedencia de los acuerdos reparatorios, siendo uno de ellos, los asuntos que se ventilan por el delitos de violencia familiar o su equivalente en las entidades federativas, en consecuencia, tal obstáculo remite a la única salida alterna para el delito en cita, establecido en el artículo 191 de la referida Ley procedimental: el de suspensión condicional, cuyo objetivo consiste en garantizar una efectiva tutela de los derechos de la víctima u ofendido y que en caso de cumplirse, pueda dar lugar a la extinción de la acción penal.

Por cuanto al delito de violencia familiar, el bien jurídico tutelado consiste en la convivencia armónica familiar, lo que se traduce en el hecho de que al cometerse acciones que traen a la vida jurídica el delito de violencia familiar, se daña la armonía del núcleo familiar, por lo que, de pretenderse obtener justicia, será necesario restaurar el bien jurídico tutelar. Surge entonces una contradicción; ¿Qué sucede en los casos en que la violencia familiar desvanece la posibilidad de reconstruir el vínculo familiar?

Es entonces que se puede manifestar que no existe justicia restaurativa (Rodríguez et al., 2010), sino se brinda a la víctima la posibilidad de "sanar" lo intangible perpetrado por la violencia; si bien, tutelar un bien jurídico consiste en la protección por medio de la norma para prevenir el daño, restaurar el daño sería entonces la correcta tutela del derecho de la víctima.

Los niños, niñas y adolescentes, dentro del marco establecido por las diferentes autoridades y organizaciones para la salvaguarda de sus derechos, primordialmente para el de una vida libre de violencia, especialmente en el ámbito familiar, remite el hecho de que, en los asuntos de violencia familiar, si los hijos no son agredidos directamente, no son referidos a proceso como víctimas, sin embargo, no es preciso que las agresiones no sean practicadas directamente en ellos.

Un núcleo familiar fragmentado, se traduce en hijos con traumas infantiles, los niños que son testigo de o son víctimas de abuso emocional o físico tienen mayor riesgo de padecer problemas de salud 
cuando sean adultos, por lo que considero que en los asuntos llevados ante el órgano jurisdiccional y vinculados por el delito de violencia familiar, en las que arribe a una suspensión condicional del proceso, deberá considerarse en las condiciones a cumplir de forma oficiosa, durante la suspensión condicional acorde con el numeral 195 del Código Nacional de Procedimientos Penales, la fracción VII, consistente en imponer al imputado: Someterse a tratamiento médico o psicológico, de preferencia en instituciones públicas; y por cuanto a la víctima el mismo derecho.

El no considerar a los niños, niñas y adolescentes como víctimas del delito de violencia familiar, es una grave omisión por parte de las autoridades responsables, recae en la inobservancia e indiferencia ante las necesidades de estos a obtener el resarcimiento de su derecho la guarda de su sanidad emocional.

Una mujer vulnerada en sus emociones, por el delito de violencia familiar, y sin la observancia de las autoridades, no cumple con lo establecido por el artículo 3 de la Ley General de Acceso de la Mujeres a una Vida Libre de Violencia, es decir; remítase el lector a una situación en donde la mujer es agredida por su pareja sentimental, en este punto no es importante el lazo legal que los una, lo que si deberá ser considerado es el hecho de que del vínculo, haya sido procreado por lo menos un hijo, entiéndase entonces que en el momento en que el fiscal del Ministerio Público, integra una Carpeta de Investigación y reúne los datos de prueba que considera acorde a la norma, serán tomados como indispensables para el dictado de un Auto de Vinculación a Proceso por el delito de Violencia Familiar, el dictamen psicológico emitido, mismo que es una constante en las carpetas de investigación y al ser verbalizado por el representante social, se concatena con el dictamen medico de lesiones, si lo hubiera y las declaración rendida por la víctima.

En continuidad con lo planteado respecto del dictamen psicológico, entiéndase entonces que toda mujer que es víctima del delito de violencia familiar, presenta alguna alteración emocional y en el mismo la Psicóloga Victimal adscrita al Centro de Procuración de Justicia, realiza recomendaciones, en las que, dependiendo de las necesidades de la víctima, acceda u un determinado número de terapias.

En ese contexto, es importante señalar que, para comprender y estimar la violencia doméstica y el daño psíquico asociado, se debe "considerar el padecimiento, consecuencias y secuelas que para la víctima tiene, y no tanto en el comportamiento e intencionalidad del agresor.” (Navarro et al., 2004).

Las consecuencias psicopatológicas más frecuentes de la violencia psicológica son (Asensi, 2008):

- Trastorno por estrés postraumático (TEPT)

- Depresión

- Trastornos de ansiedad (ansiedad generalizada, ataques de pánico, agorafobia)

- Trastornos de la alimentación

- Alteraciones del sueño

- Abuso y dependencia de sustancias

- Problemas psicosomáticos

- Baja autoestima

- Problemas crónicos de salud

- Inadaptación.

- Aislamiento.

- Problemas de relación social/familiar/laboral

- Suicidio. 
Y siendo entonces conscientes las autoridades de que la víctima del delito de violencia familiar, se coloca en estado de crisis emocional respecto de las consecuencias citadas, es entonces indispensable que las autoridades determinen el tratamiento psicológico de forma oficiosa.

Si el Juez de Control, determinó bajo la norma que existen elementos suficientes para la emisión del auto de vinculación a proceso por el delito de violencia familiar, y evidentemente, una vez que el fiscal formuló la imputación e hizo del conocimiento el hecho, deberá tener la obligación como representante social, atendiendo la particularidad de la situación, considerar a los hijos como víctimas del delito y salvaguardar el derecho a una reparación del daño psicológico.

Por tanto, no podemos hablar de justicia restaurativa, si las víctimas del delito de violencia familiar no son resarcidas del daño generado por este, el simple hecho de separar físicamente al pasivo y al activo del delito por un tiempo determinado no es suficiente para la tutela de los derechos de la víctima, muy por el contrario, coadyuva en el clima de hostilidades.

\section{DISCUSIÓN}

Con la oportunidad de brindar a las partes implicadas en el delito de violencia familiar la obtención de un tratamiento psicológico, se es posible devolver a la completa sanidad las relaciones familiares, por los hijos dejarían de juzgar a los padres y la integridad familiar, con independencia de la no existencia de un hogar, podría ser retomada.

Una separación familiar no debe ser siempre una cuestión traumática, pues para ello existen las terapias de familia; los hijos no deben vivir con el crudo recuerdo de una infancia violentada, se corre el riesgo de que el patrón de conducta se repita.

Los niños, niñas y adolescentes, al igual que las mujeres, tienen derecho a una vida libre de violencia y esta no concluye separando a las victimas de su agresor, cuando se es imprescindible o necesarias la continuidad de las relaciones interpersonales por el vínculos parental, por lo que es urgente que todos los implicados en el hecho que trajo a la vida jurídica el delito, sean considerados de forma oficiosa por la autoridades responsables, en esta caso; Jueces de Control y fiscales, como medida accesoria en las suspensiones condicionales del proceso, el tratamiento psicológico.

\section{REFERENCIAS}

1. Asensi Pérez, Laura Fátima. (2008). La prueba pericial psicológica en asuntos de violencia de género. Revista Internauta de Práctica Jurídica, (21), 15-29.

2. Cámara de Diputados. (2014a). Código Nacional de Procedimientos Penales. México. Última reforma publicada DOF 19-02-2021.

3. Cámara de Diputados. (2014b). Ley general de los derechos de niñas, niños y adolescentes. México. Última reforma publicada DOF 11-01-2021.

4. Cámara de Diputados. (1917). Constitución Política de los Estados Unidos Mexicanos. México. Última reforma publicada DOF 11-03-2021.

5. Congreso del Estado de Tabasco. (1997). Código Penal para el Estado de Tabasco.

6. González Ramírez, Isabel Ximena (2013). Justicia restaurativa en violencia intrafamiliar y de género. Revista de Derecho (Valdivia), XXVI (2),219-243.

7. Naciones Unidas. (1989). Convención sobre los Derechos del Niño.

8. Nares Hernández, José Julio, Martínez García, Dulce Gloria, Colín García, Ricardo. (2015). Violencia de género en la familia: perspectiva jurídico penal. CIENCIA ergo-sum, Revista 
Cientifica Multidisciplinaria de Prospectiva, 22(2),116-124

9. Navarro Góngora, J, Navarro abad, E., Vaquero Delgado, E. \& Carrascosa Miguel, AM. (2004). Manual de Peritaje sobre malos tratos psicológicos. Junta de Castilla y León.

10. Organización Mundial de la Salud. (2002). Informe mundial sobre la violencia y la salud. Organización Panamericana de la Salud para la Organización Mundial de la Salud: Washington, D.C.

11. Rodríguez Cely, Leonardo Alberto, Padilla Villarraga, Andrea, Rodríguez, Luz Stella, \& Díaz Colorado, Fernando (2010). Análisis de la justicia restaurativa para atender casos de violencia intrafamiliar en el Centro de Atención Integral a Víctimas de Violencia Intrafamiliar (CAVIF) de la Fiscalía General de la Nación, Colombia. Diversitas: Perspectivas en Psicología, 6(2),355-373.

12. Romero, Inmaculada. (2010). Intervención en Violencia de Género: Consideraciones en Torno al Tratamiento. Psychosocial Intervention, 19(2), 191-199.

13. Sigmund, Freud. (2020). El malestar en la cultura. Malpaso: España.

14. Taus, Patricia A. (2014). La igualdad de género y el acceso a la justicia de las mujeres víctimas de violencia en la región dentro del sistema interamericano de protección de los derechos humanos. Revista IUS, 8(34), 21-41. 